\title{
EDITORIAL
}

\section{CSE Global Theme Issue on Poverty and Human Development}

\section{Poverty and Disease Burden vs Medical Education in sub-Saharan Africa}

The decision of the Council of Science Editors (CSE) to develop a Global Theme Issue on Poverty is timely. It comes at a time when large populations in developing world continue to live on $<\$ 1$ a day and conflicts as well as natural and environmental factors continue to fuel the vicious cycle of poverty and disease. An aspect not so frequently considered is the effect of poverty on medical education and research. Although 3 of the 8 millennium development goals (MDGs) ${ }^{1}$ seek to address health medical education is not specifically addressed.

\section{Historical Background}

In the ' $60 \mathrm{~s}$ and ' $70 \mathrm{~s}$ remnants of colonial efforts sustained medical education and research in most of sub-Saharan Africa. Important researches were recorded, particularly in malaria, trypanosomiasis, meningitis, sickle cell disease and Burkitt's lymphoma, to mention a few. Institutions in Kenya, Nigeria, Sudan and produced well-trained doctors. Training of nurses and other paramedics was also comparable to other parts of the world.

Over the years poor governance, corruption, poor remuneration and armed conflicts have resulted in staggering infrastructural decay and migration of medical teachers and researchers to other more lucrative and secure parts of the world.

\section{Health Care Personnel}

Although the number of medical schools in subSaharan Africa has continued to increase, and a significantly larger number of doctors trained, many of the doctors leave the continent to Europe and North America. Despite the growth in total number of trained health personnel, Africa remains poorly staffed. $^{2}$ It has been previously noted that of the 6 world health organization regions, only Africa shows a falling doctor: population ratio, and as at 2000, it had the least ratio of 17:100,000. ${ }^{2,3}$

Indigenous postgraduate medical training began in most of sub-Saharan Africa in the ' 80 s and in West Africa and South Africa this training is now well-established. Sadly, many of these highly trained personnel leave for Europe and North America, where they are not needed. Higher level training for nurses and other paramedics does not exist in many countries.
The result is that the health care personnel left to work in sub-Saharan Africa training institutions are under motivated, often isolated and hardly encouraged by government policies. Even fewer still, are interested in medical education and training as well as research. In addition, lack of reliable data on health personnel in many countries is an important hindrance to appreciation of the burden of the problem.

\section{Standard of Training Institutions and Curriculum}

Despite the increasing number of medical training institutions the standard and quality of undergraduate training as well as training of other health personnel continue to suffer. This is largely due to:

1. Decaying infrastructure and inadequate funding

2. Few motivated and qualified medical teachers

3. Increasing number of students which is unmatched by available teaching and training facilities and resources

In addition to the above, the curriculum of many schools is largely based on colonial models, ${ }^{2,4}$ which are frequently inappropriate to local needs of the region. The curriculum has not been reviewed to reflect current needs, changing disease profile, and technology. Where the curriculum has been reviewed it is often poorly done or done by those with little or no interest, experience and commitment to medical education. The few curriculums that are properly reviewed are hardly implemented.

Postgraduate training faces limitations and challenges. The training institutions are limited in number of trainees they can enroll, largely due to inadequate funds. The trainees themselves are frequently distracted by non-training related practices to supplement earnings. Limited funding also means that only few trainees get to have any experience and exposure in a developed country training center. These factors have adverse implications for graduates of the training programmes.

\section{Research}

Currently, medical research, which is an important and integral part of medical education, is limited several factors, including: 
1. Decayed or no-existent infrastructure for laboratory research.

2. Lack of institutional, government or industrial funding for research.

3. Few interested and committed researchers

4. Feeling of financial insecurity by researchers (poor income and remuneration).

5. Feeling of isolation by researchers (poor prospects for professional development and satisfaction.
Vicious Cycle

These problems results in a relentless vicious cycle (Figure 1), which requires a global attention and commitment to disrupt. The world is now one global village than ever before and lack of progress and problems in one region has important implications for the rest of the world.

Figure 1. Vicious cycle of poverty and disease, vs medical education and research

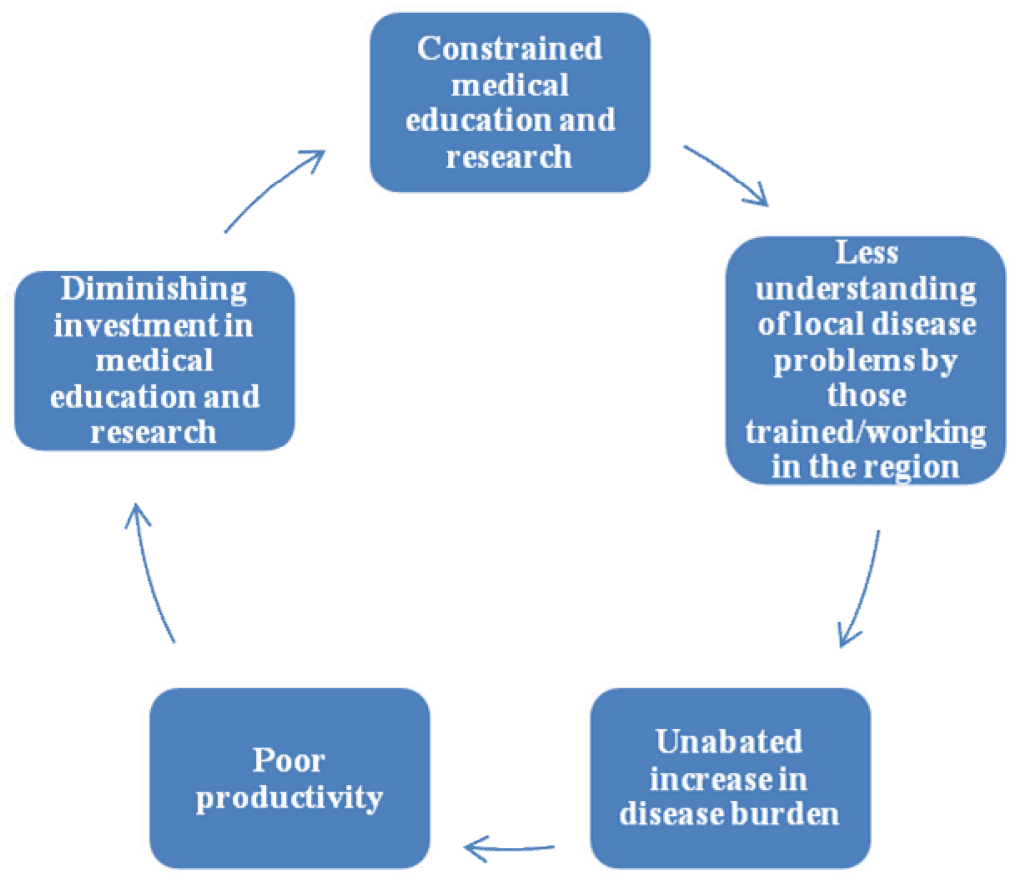

\section{What Should Be Done?}

Concerted efforts are needed if the vicious cycle is to be disrupted. The following areas are suggested to help the situation:

\section{Strengthen existing institutions}

Given the ongoing limitations, it is most important to maximize available and existing resources. Rather than embark on continuous increase in number of training institutions, existing ones should be strengthened to cope with the ever increasing number of students, changing technology and disease profile as well as research commitments. Where new institutions are considered necessary, there should be careful planning before they are established to ensure long-term sustainability and strategies to cope with future challenges should be inbuilt.

\section{Inter-institutional collaboration}

Within the same country, various institutions should collaborate and share teachers, facilities and other resources. Every existing center need not have the entire spectrum or component of staffing and facilities if collaboration is well-established. This should also help prevent a situation where one institution gets depleted to feed another.

\section{International collaboration}

Collaboration between institutions in various subSaharan African countries will be. Collaboration with developed country institutions should also help in training and continuing professional development of personnel, as well as strengthen research efforts. It should also go a long way toward removing the feeling of isolation by developing country researchers. In this regard, the twining of developing country institutions with those in developed countries should be encouraged to sustain collaborative efforts.

\section{Capacity building}

Every institution and government must embark on building a significant capacity of highly trained, wellmotivated and committed personnel. This effort should not be a one-time investment but a continuous one and should be sustained.

\section{Public-private partnership}

Obviously the public sector cannot adequately fund medical education and research alone. 
Collaboration and partnership with the private sector will help improve funding ${ }^{4}$ and needs to be developed and encouraged. This will be particularly helpful developing and sustaining infrastructure as well as relevant research.

Efforts of professional and scholarly organizations Professional associations and scholarly organizations (such as CSE) should continue to talk about the issues. This will help increase awareness and sustain pressure on governments, policy makers, the industry and the entire international community to invest positively in medical education and relevant research in sub-Saharan Africa. The effort of the CSE in this direction is encouraging.

In this issue, H. Ahmed, an experienced paediatrician from Nigeria, reviews the effects of poverty on child health and paediatric practice in Nigeria.

\author{
B. B. Shehu ${ }^{1}$ and E. A. Ameh ${ }^{2}$ \\ ${ }^{1}$ Editor-in-Chief \\ ${ }^{2}$ Assistant Editor-in-Chief
}

\section{References}

1. The Millenniem Development Goals Report. UNDP, New York, 2007.

2. Vaughan JP. Health personnel development in sub-Saharan Africa. World Bank, Washington DC, 1992.

3. Kombe G. Human resources for health challenges in dealing with HIV/AIDS in sub-Saharan Africa. http://www.PHRP.us.org

4. Ncayiyana DJ. The changing profile of medical education in South Africa. Student BMJ. 2000;08:303-306. 